\title{
Analisis ameloblastoma unilokuler menggunakan radiograf cone beam computed tomography (СВCT) 3D sebagai penunjang diagnosis
}

\author{
Siska Damayanti Saifuddin ${ }^{1 *}$, Farina Pramanik², Ria Noerianingsih Firman²
}

\begin{abstract}
Objectives: This purpose of this case report is to explain the imaging characteristics of unilocular ameloblastoma in CBCT 3D radiograph.

Case Report: A 32-year-old male patient came to the dentist complaining his painful right lower jaw over the past few days. Clinical examination showed extensive swelling in the posterior region of the right mandible to cause asymmetry at the inferior border of the mandibular corpus. Panoramic radiography showed radiolucent area in periapical mesial root of 46 tooth, extending to the right

angular mandibular with a clearly demarcated shape, and there was a root resorption of 47 tooth. CBCT 3D examination showed the presence of unilocular radiolucent lesion in a regular shape and a clear borderline, extending to the inferior border of the mandible and causing buccal-lingual cortical perforation accompanied with the resorption of adjacent 47 tooth.

Conclusion: $C B C T$ is a supporting radiography that may act as a more accurate diagnostic tool for the diagnosis of unique ameloblastoma lesions.

${ }^{1}$ Rumah Sakit Khusus Gigi Mulut (RSKGM) Kota Bandung, Bandung, Indonesia, 40115

2 Departemen Radiologi Kedokteran Gigi, Fakultas Kedokteran Gigi, Universitas Padjadjaran, Bandung, Indonesia, 40132

*Correspondence to:

Siska Damayanti Saifuddin

凶siskarskgm1@gmail.com

Received on: October 2019 Revised on: December 2019 Accepted on: January 2020
Keywords: Unilocular ameloblastoma, CBCT 3D, radiograph

Cite this article: Saifuddin SD, Pramanik F, Firman RN. Analisis ameloblastoma unilokuler menggunakan radiograf cone beam computed tomography (CBCT) 3D sebagai penunjang diagnosis. Jurnal Radiologi Dentomaksilofasial Indonesia 2019;3(3)33-7. https://doi.org/10.32793/jrdi.v3i3.443

\section{PENDAHULUAN}

Ameloblastoma merupakan neoplasma unilokular ameloblastoma terlihat gambaran total odontogenik yang bersifat agresif namun radiolusen menyerupai kista radikular. Sedangkan pertumbuhannya bersifat jinak. ${ }^{1}$ Ameloblastoma pada tipe multilokular, gambaran radiolusen berasal dari bahasa Inggris yaitu "Amel", yang disertai adanya septa-septa internal radiopak yang berati enamel, dan bahasa Yunani "Blastos", yang dapat menyerupai gambaran Honeycomb, Soapberarti benih. Ameloblastoma dikenal pertama kali dikenal pada tahun 1827 oleh Cusack. ${ }^{2}$ Tumor odontogenik ini pertama kali dideskripsikan dengan detail oleh Falkson pada tahun 1879 Ameloblastoma muncul dari sisa dental lamina dan organ gigi (epitel odontogenik) yang umumnya berlokasi di posterior ramus mandibula. ${ }^{2,3}$ Ameloblastoma unikistik umumnya mengenai kelompok usia yang lebih muda dibandingkan jenis ameloblastoma lainnya. ${ }^{3}$ Secara klinis ameloblastoma terlihat sebagai pembengkakan pada gingiva, pipi, dan palatum dengan mukosa diatasnya terlihat normal. Kebanyakan kasus, ameloblastoma tidak menimbulkan rasa sakit, sampai massa tumor membesar maka dapat menimbulkan ulkus, parasthesia, fistula dan mobilitas dan perpindahan gigi terlibat. ${ }^{1,4}$ Palpasi dapat menimbulkan hard sensation pada tulang keras atau krepitus karena tulang menipis. ${ }^{1}$

Secara radiografis, ameloblastoma terlihat sebagai lesi radiolusen dengan ukuran dan bentuk yang bervasiasi dengan tepi halus, atau scalloped; berbatas jelas dan terkortikasi dengan baik. ${ }^{4}$ Tipe
Bubble, maupun Spider-web pattern $n^{1,2,4}$

\section{LAPORAN KASUS}

Seorang pasien laki-laki berusia 32 tahun datang ke dokter gigi dengan keluhan adanya rasa sakit disertai pembengkakan pada rahang bawah kanan sejak satu tahun yang lalu. Anamnesa diketahui bahwa pasien pernah dilakukan pencabutan gigi pada regio tersebut. Hasil pemeriksaan klinis menunjukkan gigi 48 missing disertai adanya pembengkakan yang luas dari alveolar bukal, hingga ke dasar vestibulum posterior kanan dan menyebabkan asimetri pada wajah. Pasien dirujuk untuk pemeriksaan radiografi panoramik. Radiografi panoramik menunjukkan gambaran radiolusen unilokuler yang besar dengan batas jelas dan tegas pada periapikal dari mesial gigi 46 meluas hingga hampir mencapai anterior ramus hingga angulus mandibula dekstra disertasi resorpsi akar gigi 47 (Gambar 1). Selain itu, tampak adanya penipisan tulang kortikal serta ekspansi ke arah inferior dari 
border mandibula. Selanjutnya pasien dirujuk untuk pemeriksaan CBCT. Hasil pemeriksaan CBCT menunjukkan adanya lesi radiolusen disertai perforasi buko-lingual dari rahang, dan resorbsi akar gigi 47 (Gambar 2-4).

\section{DISKUSI}

Ameloblastoma merupakan suatu neoplasma yang secara klinis menunjukkan suatu tumor agresif lokal yang memiliki rekurensi tinggi. Ameloblastoma merupakan tumor yang umum terjadi, sekitar 30\% dibanding tumor odontogenik lainnya. Pada tahun 1827 Cusack pertama kali menjelaskan tumor ini. Ameloblastoma memiliki nama lain yaitu "Adamantinoma" yang pertama kali diperkenalkan oleh Mallasssez (1885) yang saat ini digunakan untuk menggambarkan tipe yang langka dari kanker tulang. Churchill menciptakan istilah "Ameloblastoma" tahun 1930. Menurut WHO, tumor ini tergolong jinak, namun memiliki kemampuan menginvasi secara lokal. ${ }^{5}$ Ameloblastoma bersifat asimtomatik yang tumbuh perlahan dan menyebabkan pembengkakan yang menyebabkan pasien membutuhkan perawatan. Ameloblastoma dapat mengenai pada usia berapa saja dengan rata-rata usia pasien berkisar 20-50 tahun, dan dapat muncul di semua lokasi pada rahang, meskipun sebagian besar berlokasi pada molar-ramus mandibula $(80 \%))^{1,6}$

Worth HM (1963) menggambarkan ada empat tipe dari ameloblastoma yang dapat dilihat secara radiografi, yakni sebagai berikut: 1) Unicystic type.

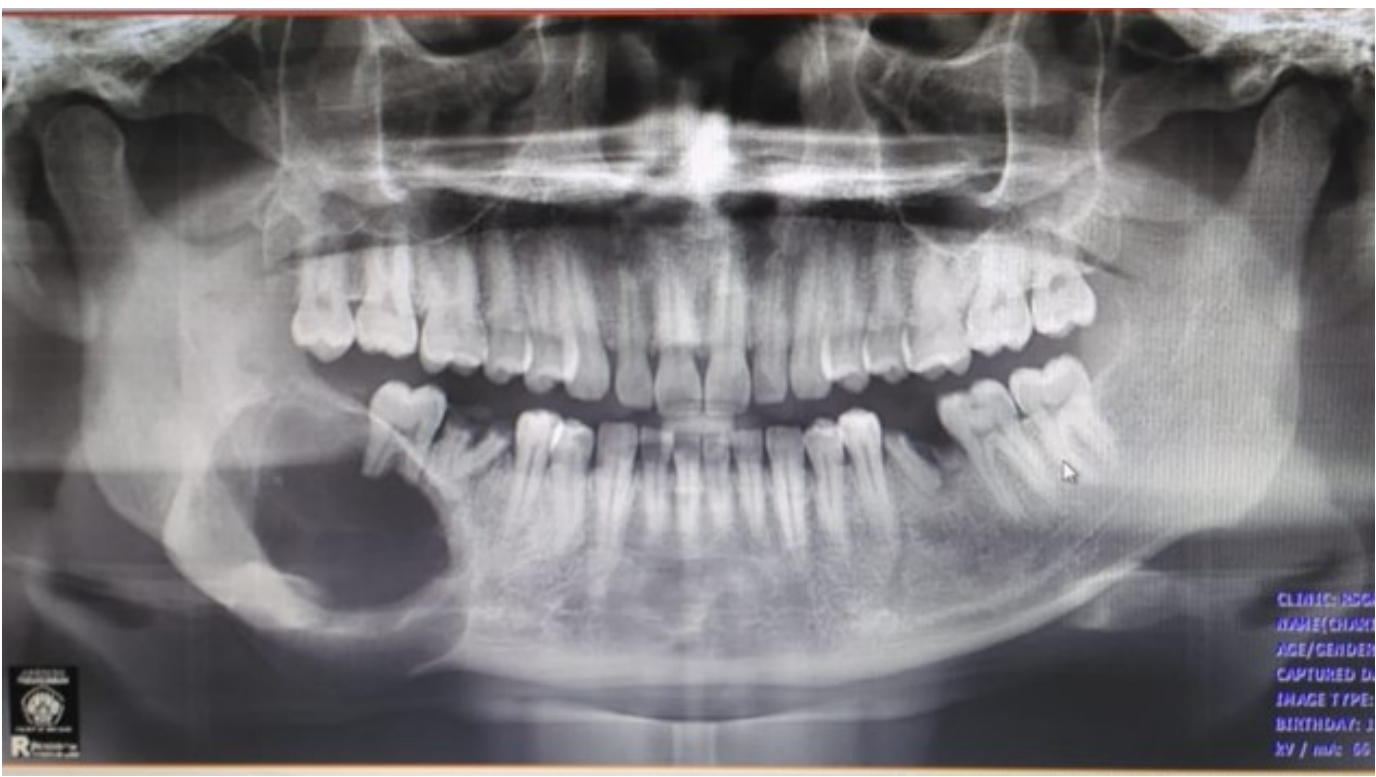

Gambar 1. Radiografi panoramik pasien menunjukkan adanya lesi radiolusen dengan batas jelas dan tegas pada regio mandibula dekstra

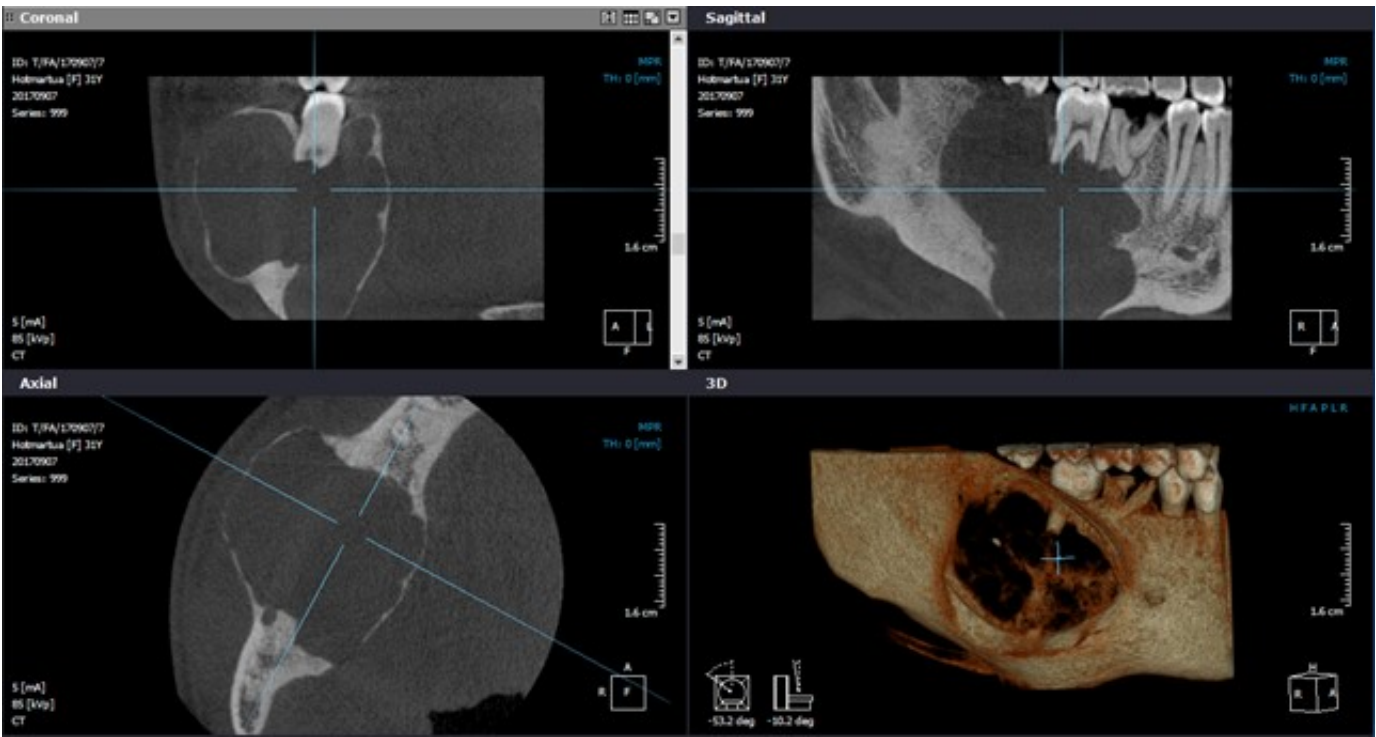

Gambar 2. Multiplanar (MPR) view radiograf CBCT pada regio mandibula dekstra 

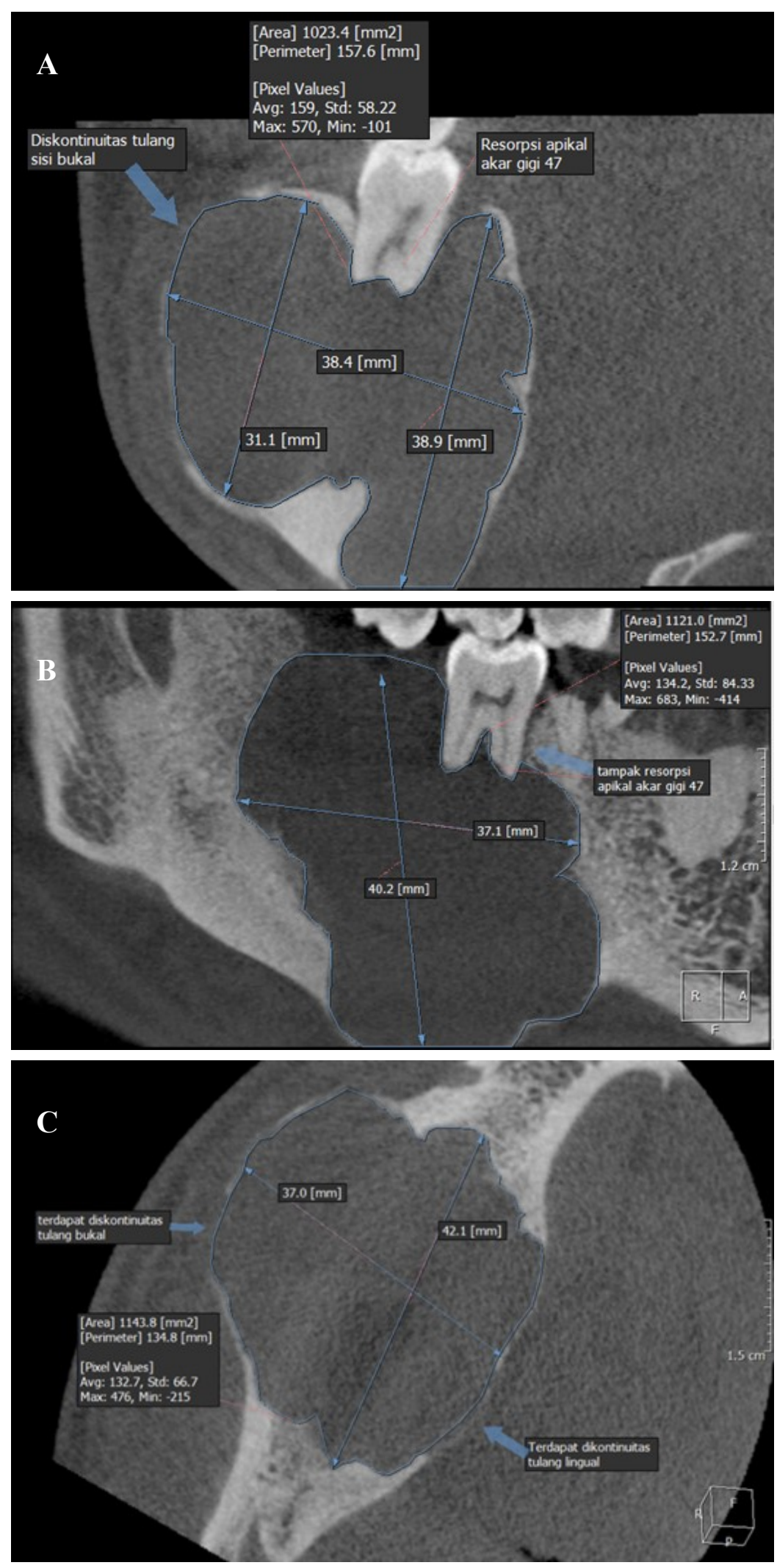

Gambar 3. Analisis lesi pada radiograf CBCT 3D, (A) Coronal view, memperlihatkan lesi radiolusen berbentuk reguler dengan batas jelas di apikal gigi 47 meluas ke bukal dan ke lingual, struktur internal radiolusen. Luas lesi (bukal-lingual) $\pm 1023,4 \mathrm{~mm} 2$ dengan lebar bukal-lingual terpanjang $38,4 \mathrm{~mm}$ dan tinggi $38,9 \mathrm{~mm}$. Densitas pixel values ROI menunjukkan nilai rata-rata 159. Tampak akar gigi 47 mengalami resorbsi. Terdapat diskontinuitas tulang sisi bukal; (B) Sagittal view, memperlihatkan lesi radiolusen berbentuk reguler dengan batas jelas dari apikal gigi 46 sampai anterior ramus mandibular. Luas lesi (mesial-distal) kurang lebih 1121,0 mm2 dengan lebar mesial-distal 37,1 mm dan tinggi 40,2 mm. Densitas pixelvalue ROI menunjukkan nilai rata-rata 134,2. Tampak akar gigi 47 mengalami resorbsi. Tampak diskontinuitas tulang kortikal basis mandibula; (C) Axial view, tampak lesi radiolusen berbentuk reguler dengan batas jelas, struktur internal radiolusen. Luas lesi kurang lebih $1143,8 \mathrm{~mm} 2$. Dengan lebar mesial-distal terpanjang $42,1 \mathrm{~mm}$ dan lebar bukal-lingual terpanjang $37,0 \mathrm{~mm}$. Tampak terdapat diskontinuitas tulang bukal dan lingual. 

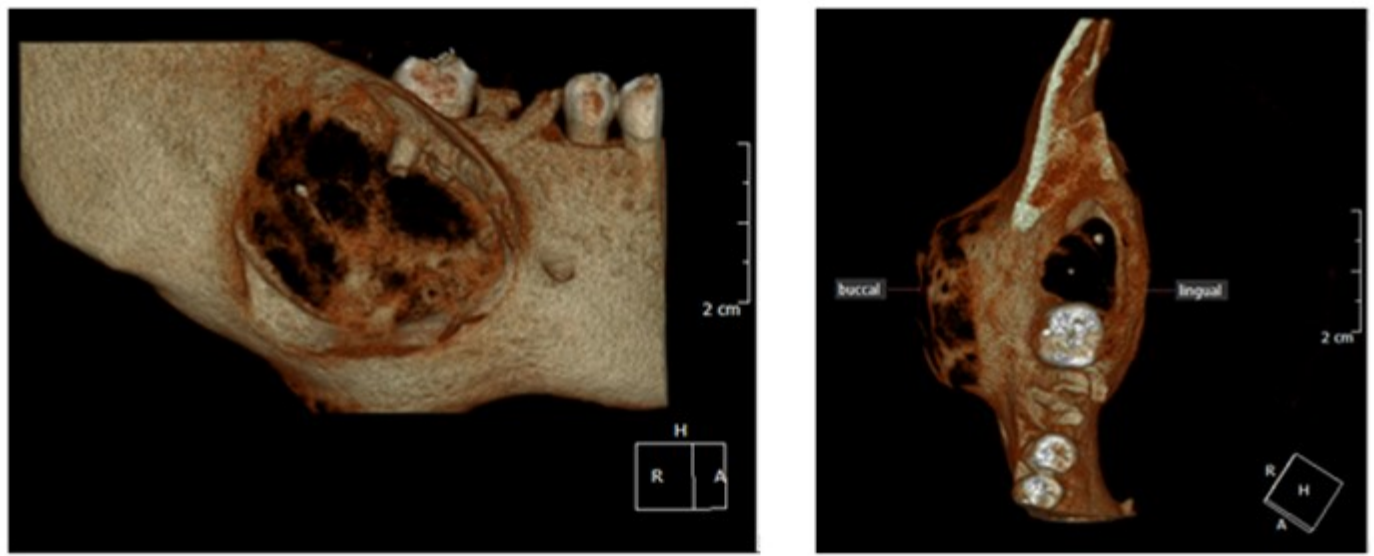

Gambar 4. 3D view radiograf $\mathrm{CBCT}$ memperlihatkan adanya lesi yang menyebabkan ekspansi rahang ke arah lateral disertai adanya perforasi dinding bukal pada posterior mandibula

Tipe ini muncul sebagai radiolusensi unilocular yang menyerupai kista. Namun, tidak seperti kista, ameloblastoma unikistik menyebabkan terputusnya kontinuitas pada tepi korteks dan bahkan dapat menunjukkan trabekula dalam lumen; 2) Spiderweb pattern. Tipe ini adalah yang paling umum ditemukan, dimana lesi terlihat sebagai area radiolusen besar dengan batas tepi yang bergerig (scallop). Dari pusat lumen, trabekula kasar menyebar ke sekeliling, sehingga menimbulkan pola seperti jaring laba-laba; 3) Soap-bubble pattern. Lesi ini terlihat sebagai radiolusensi multilokular dengan kompartemen besar dengan berbagai ukuran, sehingga menimbulkan penampilan seperti gelembung sabun, atau penampilan multi-kistik; 4) Honeycomb or solid pattern. Lesi ini disebut dengan pola sarang lebah. Tumor ini belum mengalami degenerasi menjadi kista. Oleh karena itu, beberapa radiolusen kecil terlihat dikeliling oleh korteks tulang tebal berbentuk heksagonal atau poligonal yang tebal, sehingga menimbulkan penampilan menyerupai sarang lebah. ${ }^{2}$

Pada pasien ini, dokter merujuk pasien untuk dilakukan radiografi panoramik sebagai informas tambahan untuk diagnosis awal. Hasil pemeriksaan menunjukkan adanya gambaran radiolusens unilokuler yang luas dengan batas jelas dan tegas pada periapikal dari mesial gigi 46 meluas hingga hampir mencapai anterior ramus hingga angulus mandibula dekstra, ekspansi dari inferior border mandibula dan disertasi resorpsi akar gigi 47 Suspect radiodiagnosis awal yang dipilih adalah ameloblastoma unilokuler. Hal ini sejalan dengan penelitian yang dilakukan oleh Astha Chaudhry et al., melaporkan kasus ameloblastoma sebagai daerah radiolusensi unilokuler terkait gigi molar 3 impaksi dengan tepi yang berbatas jelas dan terkortikasi dengan baik serta adanya ekspans kortikal, penipisan inferior border mandibula serta resopsi eksternal dari gigi yang terlibat. ${ }^{7}$ Penelitian yang dilakukan oleh Singer ${ }^{8}$, More dan kawankawan $^{9}$ yang meneliti 14 kasus ameloblastoma juga menunjukkan gambaran yang sama dengan kasus yang kami presentasikan.

Ameloblastoma unilokuler memiliki gambaran yang hampir sama dengan keratocystic odontogenic tumor (KOT) dimana lokasi umum yang terkena adalah posterior mandibula. KOT memiliki bentuk bulat dengan tepi halus yang terkortikasi seperti kista, namun dapat juga memperlihatkan tepi berlobus (scalloped). Struktur interna KOT adalah radiolusen, namun pada beberapa kasus dapat memperlihatkan adanya septa atau gambaran multilokuler. ${ }^{1}$ Selain KOT, kista residual juga memperlihatkan gambaran yang hampir sama dengan pasien kami. Kista residual biasanya asimtomatik dan ditemukan pada area edentulous pada pemeriksaan radiograf. Lokasi yang umum terkena adalah area mandibula, dengan gambaran radiolusen berbentuk bulat atau oval dengan tepi yang terkortikasi. Lesi ini juga dapat menyebabkan pergeseran atau resorpsi pada gigi, serta menyebabkan ekspansi tepi kortikal rahang. ${ }^{1}$

Pada kasus ini, dilakukan pemeriksaan lanjutan dengan menggunakan Cone Beam Computed Tomography (CBCT) pada regio posterior mandibula kanan. Ketersediaan pemeriksaan CBCT memungkinkan dokter untuk menilai lesi pada tingkatan yang lebih baik dibandingkan pencitraan konvensional seperti panoramik, lateral sefalometri, proyeksi anteroposterior karena CBCT dapat menampilkan arsitektur secara 3 dimensi. ${ }^{8}$ CBCT dapat memberikan informasi lebih lanjut untuk penilaian radiografis pre-operasi ameloblastoma dibandingkan dengan radiografi panoramik. ${ }^{2}$ Hasil pemeriksaan CBCT pasien kami menunjukkan adanya lesi radiolusen berbentuk reguler dengan batas jelas di apikal sisi mesial gigi 46 meluas ke bukal dan ke lingual, struktur internal radiolusen disertai resorpsi akar gigi 47 serta terdapat diskontinuitas tulang sisi bukal, lingual, dan kortikal basis mandibular (Gambar 2-4). Berdasarkan hasil pemeriksaan menggunakan CBCT, maka disimpulkan bahwa radiodiagnosis lesi tersebut adalah sebagai ameloblastoma unilokuler.

\section{SIMPULAN}

Pemeriksaan radiografi merupakan alat bantu dalam penegakkan diagnosis berbagai lesi rongga 
mulut, terutama yang melibatkan tulang rahang. Radiografi konvensional seperti panoramik dapat digunakan untuk menentukan suspek radiodiagnosis awal. Namun pemeriksaan lanjutan CBCT lebih mendapatkan informasi yang lebih baik dalam menentukan batas tepi lesi, struktur internal, ekspansi tulang kotikal dalam segala arah, dan hubungan lesi ameloblastoma dengan struktur disekitarnya. Sangat penting bagi dokter untuk mengetahui gambaran radiografi yang khas dari lesi ameloblastoma seperti gambaran struktur internal yang menyerupai honeycomb atau soap bubble dan ekspansi ke arah labial atau bukal yang dominan dengan penipisan maupun perforasi tulang kortikal pada gambar CBCT.

\section{DAFTAR PUSTAKA}

1. White S C MJP. Oral Radiology and Interpretation. 7th ed. Canada: Elsevier Inc.; 2014.

2. Supare R, Kumar RK, Sapkal R, Patel H. Cone Beam Computed Tomography ( CBCT ) As A Diagnostic Aid In A Case Of Unicystic Ameloblastoma: A Case Report. 2018;17(3):29-35. doi:10.9790/0853-1703142935

3. Farman alan G, ed. Panoramic Radiology. New York: Springer 2007. doi:10.1308/135576108783328382

4. Whaites Eric ND. Essential of Dental Radiography and Radiology. 5th ed. Toronto; 2013.

5. Bhargava A, Soni S, Tyagi A. A Large Ameloblastoma of the Mandible : a Case Report. 2014;।(V):66-72.

6. Sarment D. Cone Beam Computed Tomography Oral and Maxillofacial Diagnosis and Applications.; 2014.

7. Chaudhry A, Manjunath M, Sridevi K, Gupta I, Tanward $R$. Extensive Type III Unicystic Ameloblastoma - A Case Report with Conservative Management. 2016;15 No.3(617):202-205.

8. Singer SR, Mupparapu M, Philipone E. Cone beam computed tomography findings in a case of plexiform ameloblastoma. Quintessence Int. 2009;40(8):627-630. http:// www.ncbi.nlm.nih.gov/pubmed/19639086.

9. More C, Tailor M, Patel H, Asrani M, Thakkar K, Adalja C. Radiographic analysis of ameloblastoma: A retrospective study. Indian J Dent Res. 2012;23(5):698. doi:10.4103/0970 9290.107436

10. Citation: Dias LFT, Vian RLA, Nunes PM, Magalhaes HE, Carmo CSM, et al. Major Considerations on the Clinical, Epidemiological, Histopathological and Therapeutic Aspects of Ameloblastomas: A Systematic Review. Health Sci J 2019;Vol.13.No.3:655. 